\title{
Inovação como transição: uma abordagem para o planejamento e desenvolvimento de spin-offs acadêmicos
}

\author{
Leonardo Augusto de Vasconcelos Gomes ${ }^{\mathrm{a} *}$, Mario Sergio Salerno ${ }^{\mathrm{b}}$, \\ André Leme Fleuryc, Abraão Freires Saraiva Junior ${ }^{d}$ \\ a*lavgomes@gmail.com, PRO-EPUSP, Brasil \\ bmsalerno@usp.br, PRO-EPUSP, Brasil \\ candreleme.fleury@gmail.com, PRO-EPUSP, Brasil \\ dabraaofsjr@gmail.com, PRO-EPUSP, Brasil
}

\begin{abstract}
Resumo
Spin-off acadêmico é um tipo de nova firma que, geralmente, nasce para explorar uma inovação radical capaz de criar um novo mercado ou desafiar as regras de um setor estabelecido. Fundamentado em uma combinação de pesquisa bibliográfica, estudos de múltiplos casos e intervenções à luz da pesquisa-ação, este trabalho objetiva contribuir para a literatura de inovação e empreendedorismo em dois aspectos. Primeiro, propõe o conceito de inovação como transição em três dimensões: grau (desvio em relação a um aspecto), extensão (número de aspectos e atores envolvidos) e trajetória (sequência de inovações ao longo do tempo). A segunda contribuição é a construção de um framework com estrutura não linear e recursiva que integra a inovação ao planejamento e ao desenvolvimento do spin-off abordando o gerenciamento das incertezas. Finalmente, conclui-se que o framework proposto pode auxiliar empreendedores, investidores e universidades no desafio de criar empresas para explorar uma inovação radical.

Palavras-chave

Inovação. Planejamento. Technology roadmap. Spin-offs acadêmicos. Incerteza.
\end{abstract}

\section{Introdução}

Muitas novas firmas nascem para desenvolver e explorar comercialmente inovações que, se bem-sucedidas, serão capazes de criar ou destruir mercados, desafiar a posição de empresas estabelecidas e alterar as regras da competição de um determinado setor (Roberts, 1991). Os empreendedores, como agentes dessas mudanças, usualmente enfrentam contextos altamente mutantes, marcados por incertezas, definidas como a dificuldade em mapear e articular previamente as variáveis relevantes para o desempenho do negócio (Sommer \& Loch, 2004). A sobrevivência de uma nova firma pode estar diretamente relacionada com a capacidade de os empreendedores reestruturarem o negócio frente à emergência de incertezas relacionadas ao desenvolvimento da firma e da inovação (Sommer et al., 2009). 0 fracasso em desenvolver e comercializar a inovação pode resultar na falência precoce do empreendimento, da mesma forma que o fracasso em desenvolver a empresa pode inviabilizar o desenvolvimento da inovação (Heirman \& Clarysse, 2007).

No entanto, a pesquisa sobre planejamento e desenvolvimento de novas firmas, como os trabalhos de Brinckmann et al. (2010) e Delmar \& Shane (2003), vem se desenvolvendo de forma separada da literatura de planejamento e desenvolvimento de inovações (ex.: Cooper, 1994). Apesar dessa distância entre os dois temas, novas firmas e inovação, alguns autores recentemente têm destacado a importância dessa integração para a sobrevivência da nova firma. Heirman \& Clarysse (2007) argumentam que o desenvolvimento do primeiro produto tem forte impacto na sobrevivência e sustentabilidade do empreendimento. Por sua vez, Gomes \& Salerno (2010) 
mostram que as estratégias para o desenvolvimento da empresa impactam diretamente no processo de desenvolvimento do produto.

A dificuldade em se investigar a integração entre planejamento e desenvolvimento da inovação e da firma pode ser compreendida por pelo menos dois aspectos. 0 primeiro, mais relacionado à dimensão da firma, é que os métodos tradicionais de planejamento estratégico são mais voltados para grandes empresas (Tidd et al., 2005). Essas abordagens são indicadas, de forma geral, para ambientes mais estáveis e envolvem poucas incertezas (Mintzberg, 1994) e que são, geralmente, muito diferentes dos contextos nos quais estão inseridas as novas firmas (Roberts, 1991). 0 segundo aspecto dessa dificuldade é que grande parte das abordagens correntes de inovação está mais voltada para inovações incrementais.

Nas duas últimas décadas, pesquisadores têm convergido para a ideia de que as abordagens tradicionais de gestão de desenvolvimento de produtos, como o stage-gate (Cooper, 1994) e ferramentas de pesquisa de mercado são mais voltadas para inovações incrementais, nas quais algumas funcionalidades do produto ou processo são aprimoradas (Sarasvathy, 2001; 0'Connor, 2009). Rice et al. (2008) apontam que essas abordagens falham em tratar as incertezas presentes em projetos de produtos ou serviços com inovação radical.

Mesmo conceitualmente, pesquisadores desse campo ainda têm dificuldade em diferenciar o que é inovação incremental ou radical. Para Leifer et al. (2001), a definição de inovação radical é um produto, processo ou serviço que apresenta características de desempenho sem precedentes ou características já conhecidas que promovam melhoras significativas de desempenho ou custo e transformem os mercados existentes ou criem novos mercados. Já para Tidd et al. (2005), inovação radical pode ser algo novo para o mundo ou para a empresa. Essa última definição tende a ser imprecisa para novas firmas - como tudo é novo para esse tipo de organização, qualquer produto ou serviço poderia ser considerado uma inovação radical.

De forma fragmentada, pesquisadores de diferentes escolas têm apontado os desafios enfrentados por firmas que desenvolvem inovações radicais, a saber:

Quais são as estratégias de produto que aumentam a chance de sobrevivência do empreendimento nas fases iniciais de um mercado (Agarwal \& Bayus, 2002)?

Em quais das trajetórias tecnológicas o empreendimento deve apostar na fase pré-paradigmática de um mercado (Dosi, 1982)?

Quais competências e capacitações são necessárias para obter vantagem competitiva ainda na fase inicial do mercado (Liberman \& Montgomery, 1988)?
Apesar de essas questões estarem bem documentadas, falta ainda um referencial metodológico instrumental gerencial capaz de integrar dinamicamente o planejamento e o desenvolvimento da firma ao planejamento e ao desenvolvimento da inovação. Falta um framework que permita aos empreendedores compreenderem como ocorre a dinâmica da evolução da inovação, geralmente, de um pequeno nicho de mercado e com um conceito de produto ainda pouco desenvolvido, até o momento em que ocorre a decolagem das vendas e a inovação torna-se solução estabelecida (Geels, 2004), e que também integre essa evolução ao desenvolvimento e à operação da própria empresa.

Nesse contexto, o corrente artigo foca a articulação entre empresa e inovação, procurando responder a seguinte pergunta de pesquisa: Como empreendedores acadêmicos podem articular o planejamento e o desenvolvimento da nova firma e da inovação? Este trabalho aborda essa pergunta em um tipo específico de nova venture, no qual a integração entre esses dois processos apresenta-se como uma questão ainda mais problemática, os spin-offs acadêmicos. Essa categoria de nova empresafirma pode ser definida como organização criada para viabilizar a transferência formal e/ou informal de tecnologias e de conhecimentos gerados em instituições de ciência e tecnologia (universidades, centros de pesquisa), por meio do lançamento de produtos e serviços no mercado (Heirman \& Clarysse, 2007). A motivação para a criação da firma provém, geralmente, da expectativa de explorar uma inovação tecnológica radical (Shane, 2004).

Definidos a pergunta e o objeto de pesquisa, este trabalho se propõe a atingir dois objetivos específicos. 0 primeiro consiste em propor uma definição de inovação radical mais ampla, capaz de abarcar as questões de grau (ex.: radical versus incremental), extensão (ex.: número de atores) e trajetória (ex.: nicho até solução estabelecida), tendo em vista a natureza sistêmica e coevolutiva da inovação, que ultrapassa a visão estática e pontual (ou de projeto) implícita em alguns autores (ex.: Cooper, 1994). 0 segundo objetivo é a proposição de um framework capaz de integrar o planejamento e o estabelecimento da firma com o desenvolvimento de inovações radicais. Para isso, o presente trabalho tomará como base, no contexto dos spin-offs, um dos métodos mais reconhecidos pela literatura de inovação, o TRM - Technology Roadmapping (Phaal et al., 2004).

Para atingir os objetivos propostos, o artigo está organizado em quatro partes, além da corrente seção introdutória. A primeira é dedicada à apresentação do referencial metodológico. Na segunda parte, é discutido o referencial teórico: i) planejamento sob incerteza 
para novas firmas; ii) Technology Roadmapping; e iii) a inovação como um processo de transição. $\mathrm{Na}$ sequência, são explicitados e discutidos os resultados obtidos empiricamente, culminando com a proposição de um framework para o planejamento dinâmico em spin-offs acadêmicos. Por fim, são apresentadas conclusões, limitações da pesquisa e direções para pesquisas futuras.

\section{Referencial metodológico}

A pesquisa foi estruturada em três etapas, envolvendo doze spin-offs estudados entre 2005 e 2010 e cujos objetivos e principais resultados estão apresentados na Figura 1.

0 quadro metodológico comum nas três etapas foi composto por pesquisa bibliográfica, estudo de múltiplos casos e pesquisa-ação. A lógica dessa combinação seguiu uma abordagem interativa, envolvendo sempre revisão de literatura, estudos de casos, proposições de frameworks e testes em situações reais. 0 referencial metodológico que auxiliou na estruturação dos estudos de caso está alicerçado em Eisenhardt (1989), enquanto que, para a pesquisa-ação, foram usadas as contribuições de Thiollent (1997).
Além de terem sido realizados oito estudos de casos em spin-offs de diferentes bases tecnológicas e em diferentes estágios de desenvolvimento, foram conduzidas entrevistas semiestruturadas com os empreendedores ou responsáveis pela inovação, in loco. Em todos os casos, foram utilizadas fontes secundárias de dados, tais como planos de negócios, apresentações para investidores e sites. Foi adotado um protocolo de pesquisa comum para evitar distorções e permitir a análise dos com técnicas de triangulação entre os casos. Já nas quatro intervenções realizadas, à luz da pesquisa-ação, foram elaborados "diários de bordo” que permitiram um maior rigor metodológico para a análise dos resultados. A Tabela 1 detalha a abordagem metodológica empregada em cada spin-off.

As duas primeiras fases da pesquisa tiveram como objetivo a proposição de um framework inicial. Para tanto, a primeira fase foi consagrada a uma compreensão de como o método TRM e o T-Plan podem ser aplicados no contexto dos spin-offs, enquanto a segunda fase teve como foco maior investigar a articulação entre o planejamento e o desenvolvimento, sob incerteza, da firma e da inovação. Consolidando os resultados dessas duas fases, foi gerado um framework inicial que, a posteriori, foi completado, testado e validado, na terceira fase da pesquisa.

\begin{tabular}{|c|c|c|c|c|c|c|c|c|}
\hline \multicolumn{3}{|c|}{ Objetivo } & \multicolumn{3}{|c|}{$\begin{array}{l}\text { Compreender como os empreendedores } \\
\text { articularam o planejamento da firma ao da } \\
\text { inovação sob incerteza, por meio do TRM }\end{array}$} & \multicolumn{3}{|c|}{$\begin{array}{l}\text { Propor e testar um framework que integre } \\
\text { dinamicamente os planejamentose } \\
\text { desenvolvimentos da firma e da inovação }\end{array}$} \\
\hline Spin-off & $\begin{array}{c}\text { Base } \\
\text { tecnológica }\end{array}$ & $\begin{array}{c}\text { Método de } \\
\text { pesquisa }\end{array}$ & Spin-off & $\begin{array}{c}\text { Base } \\
\text { tecnológica }\end{array}$ & $\begin{array}{c}\text { Método de } \\
\text { pesquisa }\end{array}$ & Spin-off & $\begin{array}{c}\text { Base } \\
\text { tecnológica }\end{array}$ & $\begin{array}{l}\text { Método de } \\
\text { pesquisa }\end{array}$ \\
\hline 1 & Quimica & Estudo de caso & v & Software & Estudo de caso & IX & Automação & Estudo de caso \\
\hline II & Eletrônica & Estudo de caso & vi & Materiais & Estudo de caso & $x$ & $\begin{array}{l}\text { Equipamento } \\
\text { médico }\end{array}$ & Estudo de caso \\
\hline III & Biotecnologia & Estudo de caso & VII & Materiais & Estudo de caso & XI & Materiais & Pesquisa-ação \\
\hline IV & Quimica & Pesquisa-ação & VIII & Software & Pesquisa-ação & XII & Materiais & Pesquisa-ação \\
\hline - Diretrize & $\begin{array}{r}\text { Resultados } \\
\text { es para adaptaro TR } \\
\text { dos spin-offs }\end{array}$ & ao contexto & $\begin{array}{c}\text { - Umfr } \\
\text { - Dir } \\
\text { - } \\
\text { desenv }\end{array}$ & $\begin{array}{r}\text { Resultado } \\
\text { ramework parac } \\
\text { incert } \\
\text { etrizes para um } \\
\text { planejamento d } \\
\text { Modelagem de } \\
\text { volvimento de pr }\end{array}$ & $\begin{array}{l}\text { erenciamento de } \\
\text { as; } \\
\text { amework parao } \\
\text { lovas firmas; } \\
\text { processo de } \\
\text { dutos para spin-offs }\end{array}$ & $\begin{array}{l}\text { - Conc } \\
\text { - Um frat } \\
\text { o desen }\end{array}$ & $\begin{array}{l}\text { Resultados } \\
\text { eito de inovaçãoc } \\
\text { lework que integr } \\
\text { volvimento da firm }\end{array}$ & $\begin{array}{l}\text { no transição; } \\
\text { o planejamento e } \\
\text { ao da inovação. }\end{array}$ \\
\hline
\end{tabular}

Figura 1. Etapas da pesquisa. Fonte: elaborado pelos autores. 
Tabela 1. Síntese das abordagens metodológicas aplicadas nos spin-offs.

\begin{tabular}{|c|c|c|c|c|}
\hline Spin-off & Base tecnológica & Descrição da inovação & $\begin{array}{c}\text { Estágio de } \\
\text { desenvolvimento } \\
\text { da firma }\end{array}$ & $\begin{array}{l}\text { Abordagem metodológica } \\
\text { empregada }\end{array}$ \\
\hline 1 & Química & $\begin{array}{c}\text { Desenvolvimento de um tipo de catalisador } \\
\text { que atua em resíduos industriais }\end{array}$ & Pequena empresa & $\begin{array}{l}\text { Estudo de caso: entrevista de } \\
\text { 1h30min com o empreendedor; } \\
\text { entrevista com dois aplicadores da } \\
\text { abordagem TRM. }\end{array}$ \\
\hline 11 & Eletrônica & $\begin{array}{c}\text { Desenvolvimento de um tipo de sensor } \\
\text { inteligente para aplicações industriais e } \\
\text { comercias }\end{array}$ & Nascente & $\begin{array}{l}\text { Estudo de caso: diversas entrevistas } \\
\text { formais e informais com } 100 \% \\
\text { dos empreendedores; visita aos } \\
\text { laboratórios de pesquisa da empresa. }\end{array}$ \\
\hline 111 & Biotecnológica & $\begin{array}{c}\text { Desenvolvimento de uma armadilha para } \\
\text { vetor de uma doença tropical empregando } \\
\text { feromônios }\end{array}$ & Nascente & $\begin{array}{l}\text { Estudo de caso: entrevistas formais } \\
\text { e informais com o responsável pela } \\
\text { inovação na empresa. }\end{array}$ \\
\hline IV & Química & $\begin{array}{l}\text { Desenvolvimento de um catalisador para } \\
\text { extrair óleos essenciais diversos }\end{array}$ & Nascente & $\begin{array}{c}\text { Pesquisa-ação: intervenção durou } \\
20 \text { semanas, com reuniões semanais } \\
\text { de uma hora, além de diversas visitas } \\
\text { ao laboratório da empresa. }\end{array}$ \\
\hline $\mathrm{V}$ & Software & $\begin{array}{c}\text { Desenvolvimento de um software utilizando } \\
\text { tecnologias 3D para fins educacionais }\end{array}$ & Nascente & $\begin{array}{l}\text { Estudo de caso: entrevista de } \\
\text { 1h30min com o empreendedor. }\end{array}$ \\
\hline $\mathrm{V} 1$ & Materiais & $\begin{array}{l}\text { Desenvolvimento de um tipo de material } \\
\text { para aplicação em semicondutores }\end{array}$ & Nascente & $\begin{array}{l}\text { Estudo de caso: entrevista de } \\
\text { 1h30min com o aplicador da } \\
\text { abordagem TRM. }\end{array}$ \\
\hline $\mathrm{V} 11$ & Materiais & $\begin{array}{c}\text { Desenvolvimento de nanomaterias para } \\
\text { aplicações diversas }\end{array}$ & Estabelecida & $\begin{array}{c}\text { Estudo de caso: entrevista de } \\
\text { 1h30min com o empreendedor e com } \\
\text { o gerente de projetos. }\end{array}$ \\
\hline V111 & Internet & $\begin{array}{l}\text { Desenvolvimento de um aplicativo para } \\
\text { redes sociais }\end{array}$ & Nascente & $\begin{array}{c}\text { Pesquisa-ação: a intervenção durou } \\
3 \text { semanas, com reuniões semanais } \\
\text { de } 1 \mathrm{~h} \text {, além de diversas visitas ao } \\
\text { laboratório da empresa. }\end{array}$ \\
\hline $1 X$ & Automação & $\begin{array}{l}\text { Desenvolvimento de solução de automação } \\
\text { residencial e industrial }\end{array}$ & Nascente & $\begin{array}{l}\text { Estudo de caso: entrevista de } 2 \mathrm{~h} \text { com } \\
\text { o empreendedor. }\end{array}$ \\
\hline$x$ & Equipamentos médicos & Desenvolvimento de um equipamento & Nascente & $\begin{array}{l}\text { Estudo de caso: duas entrevistas de } \\
\text { 3h com o empreendedor. }\end{array}$ \\
\hline $\mathrm{X} 1$ & Materiais & $\begin{array}{l}\text { Desenvolvimento de um novo tipo de } \\
\text { resina }\end{array}$ & Nascente & $\begin{array}{l}\text { Pesquisa-ação: a intervenção durou } \\
28 \text { semanas, com reuniões quinzenais } \\
\text { com o empreendedor e sua equipe. }\end{array}$ \\
\hline $\mathrm{X} 11$ & Materiais & Desenvolvimento de um tipo de resina & Nascente & $\begin{array}{l}\text { Pesquisa-ação: a intervenção durou } \\
20 \text { semanas. }\end{array}$ \\
\hline
\end{tabular}

Fonte: elaborado pelos autores.

\section{Referencial teórico}

0 referencial teórico (Figura 2) da pesquisa é composto por: i) planejamento sob incerteza; ii) Technology Roadmapping; e iii) inovação como transição. 0 planejamento sob incerteza concentra-se em discutir as principais abordagens para o planejamento de novas firmas, principalmente, as que abarcam o gerenciamento de incertezas. Completando ainda essa primeira parte do referencial, é discutida a abordagem TRM, que permite alinhar a estratégia de negócio à tecnológica, o que é importante para spin-offs acadêmicos que possuem alta intensidade tecnológica. E, finalmente, é apresentado o conceito de inovação como transição, que vai além das abordagens de gestão de inovação, que se concentram mais no grau da inovação mas não contemplam, por exemplo, o número de atores envolvidos e nem a trajetória da inovação.

\subsection{Planejamento sob incerteza}

Nos últimos anos, o debate sobre planejamento de novas firmas tem convergido para a ideia de que a atividade de planejar pode gerar valor para a firma em função de auxiliar na resolução e na gestão das incertezas (Brinckmann et al., 2010). No entanto, ainda não está muito claro como as incertezas podem ser gerenciadas e nem como elas contribuem para a geração de valor para o empreendimento. Para compreender melhor essas questões, pesquisadores recorreram às pesquisas desenvolvidas no campo da gestão de projetos, que têm como foco a criação de novas firmas e o desenvolvimento de inovações radicais. Isso porque, na visão de autores como Loch et al. (2008), a criação de uma nova firma pode ser interpretada como um projeto.

Decorre que grande parte das abordagens correntes de gestão de projetos é voltada para inovações 


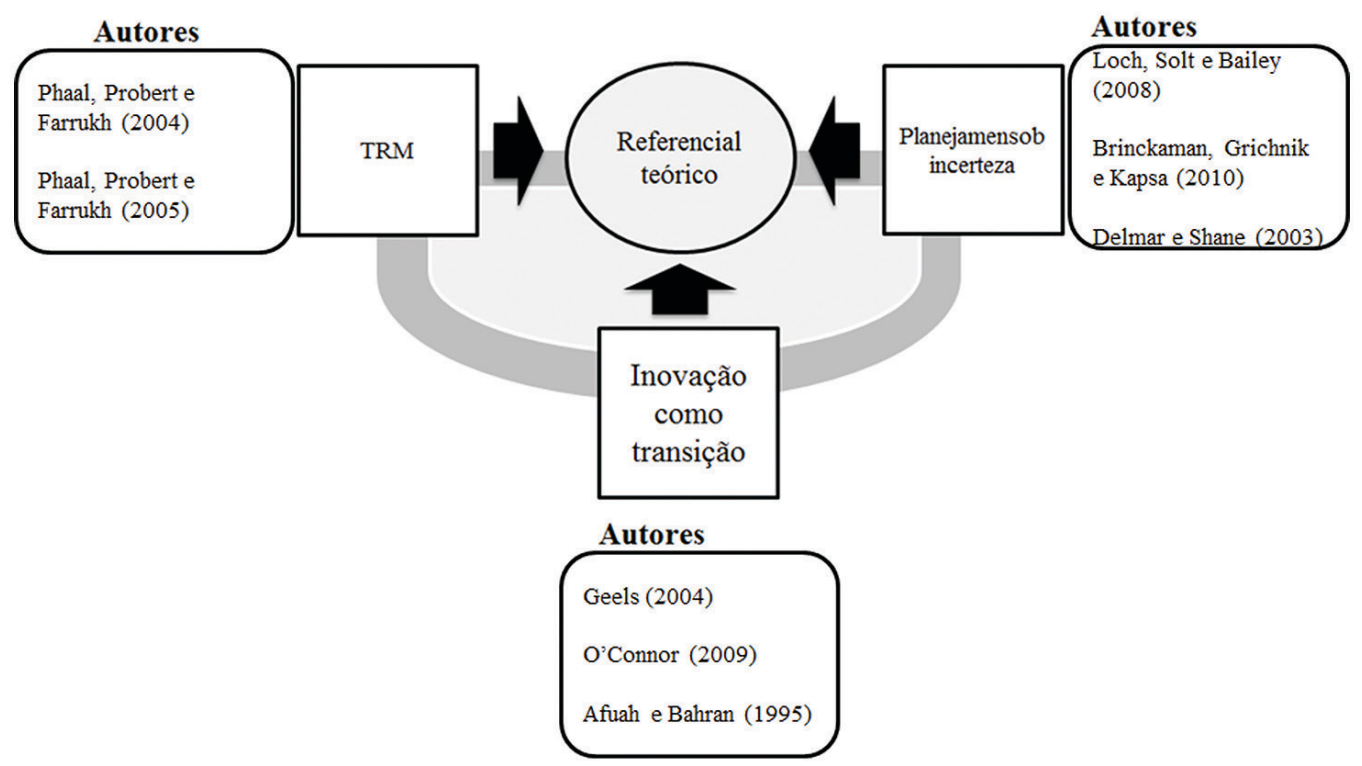

Figura 2. Referencial teórico. Fonte: elaborado pelos autores.

incrementais, que tendem a envolver poucas decisões sob incerteza (0’Connor, 2009). Pich et al. (2001) enfatizam que as abordagens tradicionais de projetos, em especial as voltadas para gerenciamento de risco, são poderosas quando a natureza do risco é bem entendida. No entanto, essas abordagens falham no tratamento das denominadas "incertezas imprevisíveis" (em inglês unforeseeable uncertainty). Pich et al. (2001) e Loch et al. (2008) definem essas incertezas do tipo unforeseeable como a dificuldade de mapear as variáveis relevantes que influenciam o desempenho do projeto e as relações funcionais entre as variáveis. Convém observar que a tradução "incerteza imprevisível" vem sendo empregada por autores brasileiros (ex.: Rabechini Junior \& Carvalho, 2012).

A Tabela 2 apresenta uma síntese da evolução da literatura de gestão de projetos no que concerne à gestão dos riscos, ou seja, a capacidade de se atribuir probabilidades aos eventos, e à gestão das incertezas imprevisíveis.

Apesar dos avanços proporcionados por essas abordagens para o planejamento de novas firmas, tais como spin-offs acadêmicos, elas focam apenas um segundo momento do processo de planejamento de um projeto. Anteriormente à identificação das incertezas, deve ser realizada a estruturação do projeto em si (Loch et al., 2008) e, no caso de spinoffs acadêmicos, essa estruturação corresponde a dois processos que se desenvolvem simultaneamente: a criação da nova firma (ex.: processos; estrutura organizacional; modelo de negócio; cultura; entre outros aspectos) e o desenvolvimento da inovação.
Para auxiliar o momento anterior à identificação das incertezas, pode-se empregar o método TRM, discutido na seção seguinte.

\subsection{Technology Roadmapping}

0 Technology Roadmapping é uma abordagem que auxilia as corporações no alinhamento entre objetivos estratégicos e gestão tecnológica, tendo em vista o planejamento das inovações em produtos e serviços (Phaal et al., 2004). Desde o desenvolvimento inicial do TRM na Motorola, na década de 1980, a abordagem do Technology Roadmapping vem passando por significativas evoluções realizadas tanto por pesquisadores quanto por praticantes, principalmente a partir de experiências no contexto de grandes organizações de diferentes setores econômicos. Essas evoluções estão associadas ao maior entendimento do processo de elaboração e de customização do roadmap (Lee \& Park, 2005), com melhor compreensão da utilização da abordagem e emprego de outras técnicas e métodos, como o desdobramento da função qualidade (Martinich, 1997) e com o desenvolvimento de diferentes orientações do roadmap, como a tecnológica (Lee et al., 2009) e a mercadológica (Phaal et al., 2004).

Há várias maneiras de se elaborar um roadmap. Para inicialização rápida na abordagem, Phaal et al. (2004) propõem o T-Plan, que consiste em um guia de elaboração de um technology roadmap baseado em workshops, conforme expõe a Figura 3.

As informações e as orientações estratégicas utilizadas durante os quatro workshops refletem 
Tabela 2. Evolução das pesquisas sobre o tratamento de risco e incerteza.

\begin{tabular}{|c|c|c|c|}
\hline Autores & Abordagem & Foco & Principais contribuições \\
\hline Chapman (1997) & Árvores probabilísticas & Variação & $\begin{array}{c}\text { Abordagem para identificação, priorização e } \\
\text { tratamento de riscos. } \\
\text { Abordagem contingencial para projetos. } \\
\text { A criação de uma nova firma segue uma estrutura de } \\
\text { milestones. }\end{array}$ \\
\hline Block \& MacMillan (1985) & Milestones & $\begin{array}{c}\text { Risco ou incerteza do tipo } \\
\text { foreseeable }\end{array}$ & $\begin{array}{l}\text { O desempenho gerencial consiste me analisar o que } \\
\text { foi aprendido e como os planejadores modificaram os } \\
\text { planos para responder às novas informações. } \\
\text { Adiar comprometimento de recurso até que evidências } \\
\text { justifiquem determinados investimentos. }\end{array}$ \\
\hline $\begin{array}{c}\text { McGrath \& MacMillan } \\
\text { (1995) }\end{array}$ & Discovery-driven & $\begin{array}{l}\text { Incerteza do tipo } \\
\text { unforeseeable }\end{array}$ & $\begin{array}{c}0 \text { planejamento em novos negócios assume que } \\
\text { suposições são estimativas que devem ser testadas e } \\
\text { questionadas. } \\
\text { Criação de valor para a firma consiste em converter } \\
\text { suposições de conhecimento. }\end{array}$ \\
\hline Rice et al. (2008) & $\begin{array}{l}\text { Planejamento do } \\
\text { aprendizado }\end{array}$ & $\begin{array}{l}\text { Incerteza do tipo } \\
\text { unforeseeable }\end{array}$ & $\begin{array}{l}\text { Quatro tipos de incertezas: técnicas, mercadológicas, } \\
\text { organizacionais e recursos. } \\
\text { Abordagem para identificação e tratamento de } \\
\text { incertezas: proposição e teste de suposições para } \\
\text { incertezas. }\end{array}$ \\
\hline Loch et al. (2008) & $\begin{array}{c}\text { Diagnósticos de } \\
\text { incertezas do tipo } \\
\text { unforeseeable }\end{array}$ & $\begin{array}{l}\text { Incerteza do tipo } \\
\text { unforeseeable }\end{array}$ & $\begin{array}{l}\text { Abordagem mais ampla de incerteza: tipo } \\
\text { unforeseeable (dificuldade de mapear as variáveis } \\
\text { chave que impactam o desempenho do projeto). } \\
\text { Proposição de um processo para diagnóstico e } \\
\text { tratamento de incertezas do tipo unforeseeable. }\end{array}$ \\
\hline
\end{tabular}

Fonte: adaptado de De Meyer et al. (2008).

Planejamento Estratégico

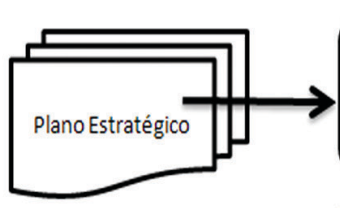

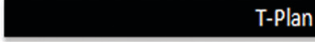

T-Plan

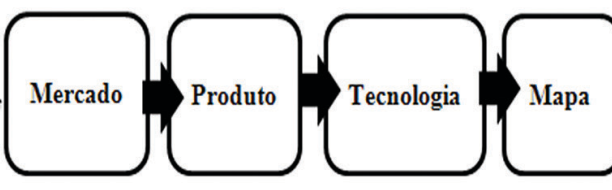

Workshop 1 Workshop 2
Workshop 3 Workshop 4

Tecnologia Elaboração do
TRM

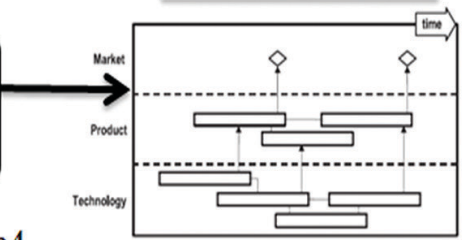

Iapa

Figura 3. Processo de elaboração do technology roadmap através do T-Plan. Fonte: adaptado de Phaal et al. (2004).

as decisões oriundas do planejamento estratégico. Phaal et al. (2005) sugerem que as empresas podem utilizar abordagens de planejamento estratégico do tipo Porter (1980) para identificar as cinco classes de forças competitivas que impactam sobre a organização, situada em determinada indústria, o que irá proporcionar uma compreensão mais profunda do contexto no qual o roadmap será desenvolvido. Uma vez realizado o planejamento estratégico e um processo de roadmapping, obtém-se o que Phaal et al. (2004) chamam de primeira versão do technology roadmap. Segundo os autores, para aumentar os benefícios do método, a empresa deverá realizar um processo de customização, adaptando o método ao seu contexto e objetivos. Para compreender o encadeamento entre o processo de planejamento estratégico, roadmapping e customização, Phaal et al. (2005) empregam o conceito de funil da estratégia, partindo de uma fase mais fluída (com muitas incertezas e muitas opções) para uma menos fluída (com poucas incertezas e opções, porém com várias restrições).

Este trabalho irá enfocar a aplicação do TRM no contexto de spin-offs, em especial a sua articulação com o planejamento da nova firma e o desenvolvimento da inovação. No tocante à nova firma, existe vasta literatura que sugere que as abordagens de planejamento estratégico do tipo Porter (1980) são mais adequadas para firmas estabelecidas de grande porte e em contextos mais estáveis e já existentes, com mercados estabelecidos, cadeias produtivas consolidadas, clientes e concorrentes conhecidos (Mintzberg, 1994). 0 contexto dos spin-offs exige abordagens para lidar com incertezas, não linearidade e o novo (Vohora et al., 2004). Para tanto, serão utilizadas as principais contribuições propostas pelos autores de gestão de projetos sob incerteza e risco. 
Já em relação à inovação (objeto de discussão da próxima seção), será investigada a articulação do TRM ao conceito de inovação como transição, em especial a sua visão tecnológica e social. Parte da literatura que trata do TRM adota uma perspectiva neoclássica da questão: informação perfeita; curva "S" de tecnologia; e racionalidade perfeita dos atores. Verbong \& Geels (2010) apresentam um conjunto de críticas às técnicas correntes de análise de cenários, que pode ser estendido ao TRM: mais ênfase aos estados finais do que aos caminhos dinâmicos para se chegar aos eventuais estados finais; salienta mais a dimensão tecnologia do que a dinâmica social e o contexto; dificuldade em lidar com transições e descontinuidades; mais ênfase a critérios econômicos (preço, investimento, demandas e custos/despesas) do que sociais, como crenças e disputas entre vários indivíduos e grupos sociais.

\subsection{Inovação como transição}

No corrente estudo, considera-se que a inovação visa provocar uma transição em um conjunto de aspectos (ex.: no mercado, na tecnologia, no produto, no modelo de negócio), sendo mais ou menos radical de acordo com o grau, a extensão e a trajetória da transição que ela pode representar. Quanto maior o grau e a extensão da transição e quanto mais no início da trajetória a inovação se encontrar, maiores serão as incertezas presentes, maior é número de atores envolvidos e maior deve ser o espaço para o aprendizado (Geels, 2004). Diferenciar essas três características permite aos empreendedores compreender de forma mais integrada o desenvolvimento, uso e difusão da inovação.

Uma inovação pode ser radical para o cliente, mas ser incremental para os fornecedores (Afuah \& Bahran, 1995). Isto implica que a inovação pode representar uma transição em um determinado aspecto (ex.: prática dos usuários), mas sem necessariamente modificar outros aspectos (ex.: modelo de negócio praticado). Dessa forma, o grau refere-se à intensidade da transição que a inovação provoca em um determinado aspecto, enquanto a extensão refere-se ao número de aspectos que uma inovação pode modificar, ao número de atores envolvidos e o que muda para cada um desses atores.

A extensão também procura captar o caráter sistêmico da inovação não apenas na sua produção, mas no seu uso e na sua difusão. 0 desenvolvimento de uma inovação pode envolver a modificação ou surgimento de grandes sistemas tecnológicos (Hughes, 1987), a criação de novos mercados (O'Connor, 2009), como internet, novas fontes de energia, automóveis, computadores etc. (Geels, 2004), envolvendo um amplo conjunto de atores, como universidades, empresas, formuladores de políticas públicas, organizações não governamentais, entre outros.

Alguns autores defendem a ideia de que as empresas adotem uma perspectiva mais sistêmica para o processo de desenvolvimento de inovações. Adner \& Kapoor (2010) vêm procurando desenvolver conceitos mais amplos de estratégia e competição, como a ideia de "ecossistemas" de negócios e inovação, para mostrar que o sucesso de uma inovação não depende apenas de uma única firma. Nesse sentido, entende-se que não é suficiente apenas desenvolver a inovação, é preciso criar um ecossistema para aprimorá-la, difundi-la e complementa-la. Em outras palavras, pode-se dizer que o desenvolvimento depende do ecossistema, da rede de relações da empresa e de seus empreendedores.

A terceira característica consiste na ideia de que toda inovação segue uma trajetória. A ideia de trajetória foi inicialmente proposta por Dosi (1982), que focou aspectos tecnológicos. Para fins da corrente pesquisa, considera-se que a trajetória vai além da tecnologia. 0 argumento desenvolvido aqui é que 0 surgimento, o desenvolvimento e o sucesso de uma inovação seguem uma trajetória ou um processo coevolucionário, no qual tecnologias e instituições se tornam intrinsecamente parte de uma mesma dinâmica de desenvolvimento (Nelson \& Sampat, 2001). Para que uma inovação obtenha sucesso, é necessário um processo de coevolução, por exemplo, entre: mercado e tecnologia (Lundvall, 1988); tecnologia, estrutura industrial e políticas públicas (Leydesdorff \& Etzkowitz, 1998); entre outras.

Outro autor que também discute essa ideia da coevolução é Geels (2004). Esse autor propõe um framework, a perspectiva multinível, que permite compreender analítica e conceitualmente a evolução e a coevolução de inovações (Figura 4).

Os seguintes níveis compõem a perspectiva multinivel proposta por Geels (2004):

Panorama (landscape): Uma estrutura externa ou um contexto para a interação entre os atores que influencia o comportamento mas não pode ser modificado pelos atores.

Regimes sociotécnicos (patchwork of regimes): Referem-se a elementos (ex.: regras, recursos etc.) que permitem e constringem a atividade dentro de determinada comunidade, diferentemente do "panorama", que se refere aos fatores externos mais amplos. Geels (2004) aponta que os regimes sociotécnicos são compostos por cinco regimes: i) tecnológico e de produto; ii) da ciência; iii) da política; iv) sociocultural; v) de usuários, mercado e redes de 


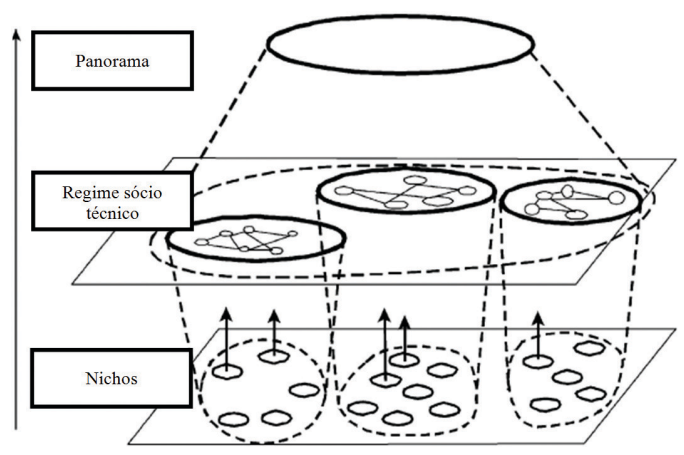

Figura 4. Perspectiva multinivel. Fonte: Geels (2004).

distribuição. Cada um desses regimes se organiza em torno de tipos de regras/instituições.

Nichos tecnológicos (niches): Vistos como locus de incubação e desenvolvimento de inovações radicais (Geels, 2004). Nichos são locações que desviam-se das regras do regime prevalecente. Podem ser formados por pequenos mercados, com critérios de seleção baseados em alto desempenho de tecnologia, produto ou serviço. As regras são menos claras e articuladas em nichos e as incertezas presentes em um nicho podem ser diversas, incluindo aquelas relacionadas aos aspectos técnicos e às heurísticas de buscas.

A perspectiva apresentada na Figura 4 permite compreender analítica e visualmente o conceito de inovação como transição, com uma dimensão temporal incluída. Nichos são mais ou menos radicais de acordo que a intensidade (grau) e o número (extensão) de regras de que eles se desviam (Geels, 2004). Já a trajetória da inovação pode envolver, por exemplo, as relações entre os atores, que tendem a ser pouco claras, mas, com o processo de coevolução ao longo do tempo, as regras e as relações entre os atores podem crescer e estabilizarem-se, como resultado de um processo bem-sucedido de aprendizado (Geels, 2004).

Como será discutido na próxima seção, esse conceito de inovação como transição permite compreender de que maneira empreendedores planejam e desenvolvem a firma até o momento em que ocorre a explosão das vendas.

\section{Proposição do framework que integra o planejamento e o estabelecimento da firma com o planejamento e o desenvolvimento da inovação}

As pesquisas conduzidas nas fases 1 e 11 mostraram que o planejamento e o desenvolvimento dos spin-offs não apenas afetam e são afetados pelo desenvolvimento do primeiro produto em si mas pelas múltiplas gerações de produtos até o momento em que ocorre a decolagem das vendas. As firmas investigadas modificaram-se (ex.: em termos de recursos e competências) para acompanhar ou aproveitar a trajetória que a inovação seguiu (do nicho até a solução estabelecida).

0 planejamento dos spin-offs também não esteve restrito ao empreendimento em si. De acordo com a extensão que as inovações provocaram, as firmas necessitaram planejar e construir um ecossistema de atores. No caso do spin-off 111, os empreendedores tiveram que construir um ecossistema, ainda na ciência, para influenciar pesquisadores a evoluir na compreensão do problema e da tecnologia da empresa. Por sua vez, para serem capazes de produzir o seu produto, os empreendedores do spin-off $\vee$ perceberam que teriam de construir uma cadeia produtiva e, posteriormente, qualificar os seus fornecedores.

Os resultados das duas primeiras fases da pesquisa mostraram que a adaptação do TRM ao contexto dos spin-offs deveria articular as dimensões "firma", "inovação como transição" e "incertezas", conforme apresenta o framework proposto (Figura 5). Isso porque as firmas estudadas impactavam e eram impactadas pelo desenvolvimento da inovação. Da mesma forma, as incertezas na dimensão da inovação influenciavam e eram influenciadas pelas incertezas presentes no desenvolvimento da firma. Tanto os planejamentos da firma quanto os da inovação apresentaram, nos estudos de casos, uma estrutura não linear e recursiva. Em outras palavras, empreendedores constantemente tiveram que replanejar a firma e a inovação mediante a emergência de incertezas.

As três partes do framework estão interrelacionadas. A parte A é consagrada ao planejamento e ao gerenciamento da transição (PGT). A parte B destina-se ao gerenciamento das incertezas (Gl) presentes na parte A e na implantação da estratégia. Já a parte $\mathrm{C}$ representa graficamente o planejamento tecnológico e estratégico.

\subsection{Parte A - Planejamento e gerenciamento da transição}

A parte A, planejamento e gerenciamento da transição, representa uma oportunidade para os empreendedores aprenderem sobre a nova firma e sobre a inovação, compreendendo como essa pode causar uma eventual transição em termos de: i) aprender com o mercado; ii) aprender com o produto; iii) aprender com a tecnologia e a ciência; iv) aprender com os recursos, capacitações e competências. A proposição dessas quatro etapas está baseada nos estudos de caso e intervenções realizados, que mostraram que o PGT poderia ser organizado em quatro grandes etapas. 
Mais do que explicar cada uma das etapas do PGT, este artigo irá focar na lógica comum a elas, ilustrada na Figura 6. Essa lógica segue a estrutura da perspectiva sociotécnica multinível (Geels, 2004), composta por: landscape (atividade 1), regime sociotécnico (atividade 2), nicho (atividades 4, 5, 6) e a transição (atividade 3 e 7). Para aplicar qualquer etapa do PGT, recomenda-se executar as sete atividades descritas na Figura 6.

Atividade 1: Consiste em compreender quais são as pressões do landscape e como essas podem afetar ou estão afetando o regime sociotécnico atual. Essas pressões podem ter naturezas diversas, tais como econômicas, sociológicas, concorrenciais, mudanças na regulamentação, modificações no comportamento dos consumidores, entre outras. Essa primeira atividade permite aos empreendedores compor um panorama de possíveis forças incontroláveis e exógenas que estão provocando ou poderão provocar mudanças no regime sociotécnico, criando janelas de oportunidade (Geels, 2002).

Atividade 2: Consiste na identificação de quais são os direcionadores (regras e instituições) que dirigem o regime sociotécnico. Por exemplo, no spin-off Xl, na dimensão "aprendendo com o mercado", essa atividade concerniu às regras de competição, à infraestrutura para produzir, distribuir e comercializar a inovação, ao conhecimento dos segmentos atuais de mercado e necessidades atuais e futuras dos clientes.

Atividade 3: Visa explicitar quais direcionadores a inovação poderá eventualmente mudar e criar. Por exemplo, na dimensão "aprendendo com o produto e o serviço", esses direcionadores podem estar ligados a novos requisitos técnicos do produto ou a novas necessidades a serem atendidas. Os empreendedores devem avaliar o grau da transição que a inovação irá provocar em cada uma das dimensões e seus respectivos direcionadores. Quanto maior for o desvio entre a inovação e o regime atual, maior será a possibilidade de enfrentar incertezas de natureza mais alta (imprevisíveis e caos) e maior deverá ser o espaço para o aprendizado. Por exemplo, no spin-off Xl1, a transição provocada pela inovação não consiste apenas na rota tecnológica para produzir a resina renovável ao invés da fóssil (petróleo), mas no conceito do produto, perfil do cliente e no processo

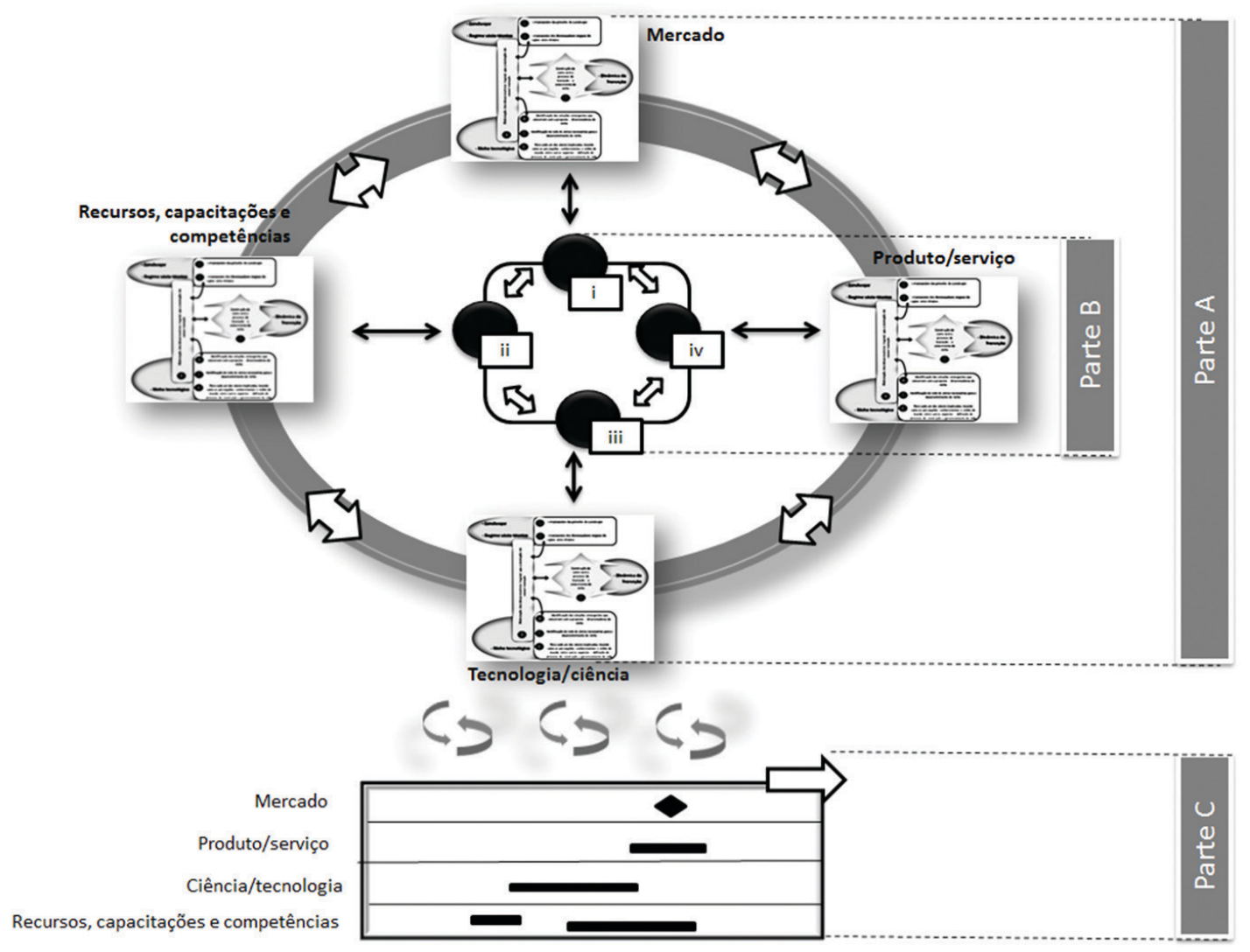

Figura 5. Framework proposto. Fonte: elaborado pelos autores. 


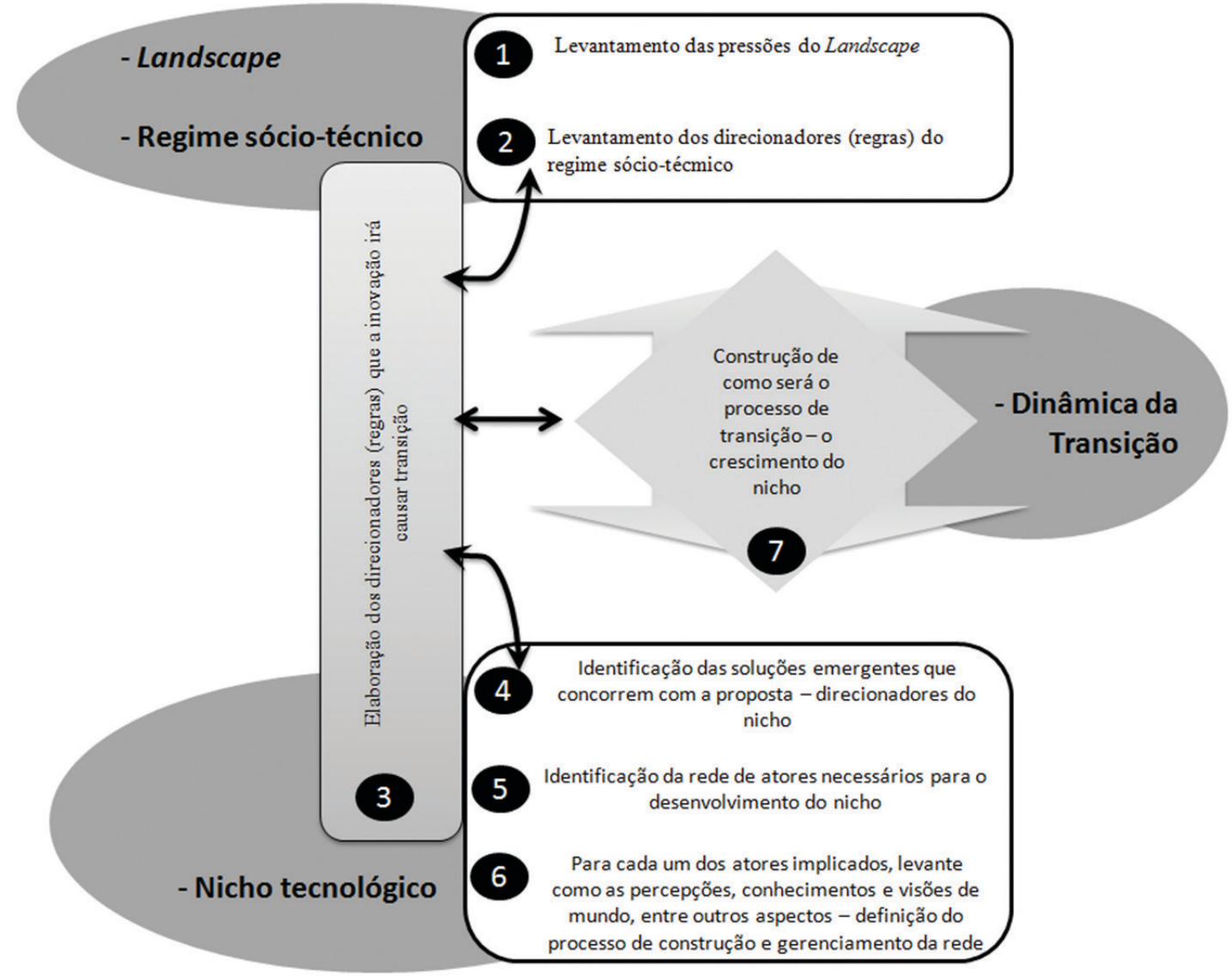

Figura 6. Arquitetura básica do roadmap para cada dimensão da transição. Fonte: elaborado pelos autores.

produtivo, que possui novas tecnologias para lidar com agentes biológicos.

Atividade 4: É voltada para a identificação dos direcionadores provisórios do nicho e das soluções que concorrem e complementam a inovação pretendida. A pesquisa de campo mostrou que a identificação desses direcionadores envolve o tratamento de informações contraditórias e fragmentadas, com "visões de mundo" distintas e incertezas. Parte dessa dificuldade em identificar os direcionadores está relacionada ao fato de que nem sempre a competição está restrita entre o nicho e o regime.

0 caso do spin-off Xll pode ilustrar o tipo e o grau de competição e cooperação no nicho. 0 desenvolvimento de seu produto (um tipo de resina verde) está ocorrendo em uma corrida tecnológica e mercadológica de espectro global. Existe um conjunto de empresas que está procurando mudar a rota tecnológica fóssil para uma das possíveis rotas renováveis, incluindo combustíveis renováveis, agentes biológicos, entre outras. As empresas inseridas nesse conjunto competem entre si de diferentes formas, ainda nessa fase do processo de desenvolvimento da inovação. Por exemplo, esse spin-off está desenvolvendo pesquisas em diferentes rotas ou trajetórias tecnológicas e patenteando os resultados no intuito de bloquear seus concorrentes, ao mesmo tempo em que coopera com alguns desses concorrentes, no intuito de juntos competirem contra outro conjunto de empresas que está procurando modificar não apenas a fonte do produto, mas também torná-lo biodegradável.

Vários instrumentos e ações empregados nessas estratégias de competição e cooperação foram identificados em campo (spin-offs III, IV, V, VII, $\mathrm{V}$ III, X): Influenciar na agenda de pesquisa e na formulação de políticas públicas; elaboração de relatórios científicos em prol de uma determinada solução; veiculação de propaganda em diferentes mídias contra uma solução etc. Na visão clássica da literatura de inovação, a difusão do produto e das suas características ocorre apenas na fase de seu lançamento (ex.: Cooper, 1994). No caso do spin-off $\mathrm{Xl}$, a difusão ocorreu antes mesmo do término do 
desenvolvimento do produto, numa tentativa de construir as necessidades dos clientes.

A Tabela 3 apresenta alguns exemplos de pontos que podem orientar a análise nas quatro etapas iniciais do gerenciamento da transição.

Atividade 5: Visa construir um ecossistema da inovação e do negócio, identificando os atores que fazem parte do nicho e quais eles julgam necessários para o seu crescimento. Nem sempre é muito claro quem são os atores que compõem o nicho, como foi no caso dos spin-offs Il, Vl, Vll, VIIl, Xl e Xll. As fronteiras do nicho tendem a ser tênues e de difícil delimitação. Os casos (II, VII, VIIl e XI) mostraram que o nicho é geralmente composto pelos usuários líderes de uma tecnologia (clientes), empresas pioneiras, outras startups e spin-offs acadêmicos, organizações não governamentais, formuladores de políticas públicas, entre outros. 0 entendimento da dinâmica do crescimento foi importante aspecto do desenho dos atores que constituem o nicho nas duas intervenções (spin-offs $\mathrm{XI}$ e XII). 0 perfil dos usuários líderes pode ser diferente do perfil dos clientes finais da inovação quando ocorre a decolagem das vendas, como ocorreu no spin-off 11. Os empreendedores devem estar abertos à experimentação e à vigilância constante para identificar novos clientes e novas oportunidades.

Atividade 6: Consiste na construção e gerenciamento da rede. Nesse sentido, os empreendedores devem procurar identificar as visões de mundo e os modelos mentais dos atores; as relações de poder; as suas expectativas; os problemas de agenda; o conhecimento e a capacidade de aprender; o domínio sobre recursos essenciais e complementares necessários para o desenvolvimento e sucesso da inovação. Na dimensão "aprendendo com o produto e o serviço", empreendedores do spin-off VIl definiram estratégias e processos para gerenciar a inovação de uma forma aberta e em rede, envolvendo todo um ecossistema de atores.

Esse processo de inovação aberta não se refere apenas ao desenvolvimento do corpo principal da inovação, mas também aos seus ativos complementares. Por exemplo, a inovação do spin-off $\mathrm{Xl}$ exigia o desenvolvimento de um conjunto complementar de produtos e serviços para torná-la viável. Os empreendedores, nesse caso, realizaram esforços deliberados para influenciar a agenda de outras empresas para desenvolverem esses ativos complementares. Há casos históricos que também ilustram isso. A difusão da lâmpada elétrica, por exemplo, exigiu não apenas a produção de mais lâmpadas, mas o aumento da infraestrutura de produção e distribuição de energia, o desenvolvimento de mecanismo de medição e controle do consumo de eletricidade (Utterback, 1994).

Convém observar que os empreendedores devem procurar estabelecer diferentes estratégias para os diferentes atores que compõem a rede, em um processo de gestão multiparadigmática. Nos estudos de caso das fases 11 e 111 , os empreendedores apresentaram dificuldades em coordenar atores muito diferentes, tais como universidades, instituições e agentes políticos, empresas emergentes e grandes empresas. Os spin-offs

Tabela 3. Exemplo de pontos que poderão ser analisados nas quatro dimensões da transição

\begin{tabular}{|c|c|c|c|c|}
\hline Atividades & Mercado & Produto e serviço & Tecnologia e ciência & $\begin{array}{l}\text { Recursos, capacitações e } \\
\text { competências }\end{array}$ \\
\hline Atividade 1 & \multicolumn{4}{|c|}{ Mudança nos hábitos do consumidor; pressões pela sustentabilidade; mudanças nas leis; políticas públicas } \\
\hline Atividade 2 & $\begin{array}{c}\text { Modelos de negócios } \\
\text { praticados; regras de } \\
\text { competição; perfis dos } \\
\text { clientes; governança na } \\
\text { cadeia de suprimentos; } \\
\text { infraestrutura de produção } \\
\text { e distribuição; segmentos } \\
\text { de mercado cobertos pelos } \\
\text { concorrentes }\end{array}$ & $\begin{array}{c}\text { Requisitos atuais dos } \\
\text { produtos; necessidades } \\
\text { atendidas dos clientes; } \\
\text { estratégias de plataformas de } \\
\text { produtos utilizadas }\end{array}$ & $\begin{array}{l}\text { Trajetórias tecnológicas } \\
\text { atuais; paradigmas } \\
\text { tecnológicos atuais; } \\
\text { heurísticas de busca }\end{array}$ & $\begin{array}{l}\text { Recursos, capacitações e } \\
\text { competências para competir } \\
\text { no regime atual; ativos } \\
\text { complementares para obter } \\
\text { lucro com a inovação }\end{array}$ \\
\hline Atividade 3 & $\begin{array}{l}\text { Cria um novo modelo de } \\
\text { negócio; muda as regras do } \\
\text { jogo; cria novas funções na } \\
\text { cadeia de valor; cria novos } \\
\text { mercados }\end{array}$ & $\begin{array}{c}\text { Cria novos requisitos; cria } \\
\text { novas necessidades; atende } \\
\text { um novo conjunto de } \\
\text { clientes; modifica heurísticas } \\
\text { básicas }\end{array}$ & $\begin{array}{l}\text { Cria nova trajetória } \\
\text { tecnológica; muda princípios } \\
\text { científicos; cria novo } \\
\text { paradigma }\end{array}$ & $\begin{array}{l}\text { Novos recursos, capacitações } \\
\text { e competências que a } \\
\text { inovação vai demandar do } \\
\text { inovador, de fornecedores e } \\
\text { clientes }\end{array}$ \\
\hline Atividade 4 & $\begin{array}{l}\text { Soluções que competem com } \\
\text { a empresa; soluções que } \\
\text { complementam; necessidades } \\
\text { que cada uma dessas soluções } \\
\text { atendem provisoriamente }\end{array}$ & $\begin{array}{c}\text { Requisitos que as soluções } \\
\text { emergentes atendem; } \\
\text { características dos usuários } \\
\text { líderes de cada solução; } \\
\text { problemas a serem resolvidos; } \\
\text { heurísticas de busca } \\
\text { provisórias }\end{array}$ & $\begin{array}{c}\text { Trajetórias tecnológicas } \\
\text { emergentes; heurísticas de } \\
\text { busca; identificação de sinais } \\
\text { fracos }\end{array}$ & $\begin{array}{l}\text { Recursos, capacitações e } \\
\text { competências para competir } \\
\text { no regime atual; ativos } \\
\text { complementares para obter } \\
\text { lucro com a inovação }\end{array}$ \\
\hline
\end{tabular}


tiveram dificuldades com a falta de legitimidade e de credibilidade para construir as relações necessárias ao desenvolvimento das dimensões do nicho. Para auxiliar tanto na identificação das fronteiras provisórias do nicho quanto na construção da rede do nicho, os empreendedores empregaram diferentes estratégias, tal como a exposição e o estabelecimento de parcerias estratégicas para conferir maior credibilidade e legitimidade, visando compensar a falta de capital social (e muitas vezes econômico) dos empreendedores.

Atividade 7: É voltada para a dinâmica da transição, envolvendo a concepção de eventuais trajetórias de crescimento do nicho, identificação dos milestones da transição. Há pelo menos dois pontos a serem observados. 0 primeiro é o entendimento da coevolução em cada uma das dimensões da transição e entre as dimensões da transição (ex.: dimensão mercado e dimensão produto e serviço). Isso pode envolver a identificação dos problemas e dos desafios que deverão ser superados para que a inovação obtenha êxito. Na dimensão "recursos, capacitações e competências", os empreendedores do spin-off XIl identificaram quais capacitações dinâmicas a empresa e o ecossistema deveriam desenvolver para o crescimento da rede do nicho, para competição e cooperação no nicho e para competição entre nicho e regime. Por fim, o segundo ponto consiste na definição dos milestones da transição em uma perspectiva sistêmica, analisando a transição em seu todo e em cada uma das dimensões.

\subsection{Parte B - Gerenciamento das incertezas}

0 processo de gerenciamento das incertezas (Gl) é um processo auxiliar e paralelo ao planejamento e gerenciamento da transição e, consequentemente, ao TRM. Empreendedores podem aplicar esse processo durante a operacionalização do PGT e do TRM. Por exemplo, no spin-off $\mathrm{Xl}$, após realizar as sete etapas em uma dada dimensão, os empreendedores empregaram o Gl para identificar e gerenciar as incertezas daquela dimensão. Já no spin-off XII, os empreendedores aplicaram o $\mathrm{Gl}$ após analisar a forma pela qual a inovação iria provocar uma transição em todas as dimensões.

0 PGT, o TRM e o $\mathrm{Gl}$ adotam as ideias de estado do mundo e estado do conhecimento. Isso implica que a emergência de novas informações e incertezas, o aprendizado obtido na implantação do PGT e do TRM e novos conhecimentos adquiridos pelos empreendedores poderão exigir não apenas modificações no $\mathrm{Gl}$, mas também modificações no PGT e no TRM.

0 framework integrado permite aos empreendedores não apenas ter um registro do que é conhecido e do que não é conhecido, mas também da dinâmica do processo de planejamento e desenvolvimento, segundo os diferentes estados do mundo e do conhecimento que o spin-off atravessará.

Nas aplicações do framework nos spin-offs Xl e XIl, o PGT pôde ser visto como um conjunto interrelacionado de subproblemas, enquanto o $\mathrm{Gl}$ envolveu o gerenciamento das incertezas de diferentes graus presentes em cada subproblema. A Figura 7 apresenta a estrutura do Gl.

A primeira etapa consiste na identificação do tipo de incerteza associada a cada subproblema e seus componentes: decisões, suposições, variáveis etc. A etapa 11 consiste na definição de um grau de prioridade da incerteza, da elaboração de suposições para cada incerteza e de quando será desenvolvida alguma ação gerencial para tratá-la. Essa última atividade consiste em definir um conjunto de milestones para tratarem-se as incertezas. Já a etapa 111 está relacionada com a definição da abordagem de gerenciamento mais adequada segundo a natureza da incerteza. A Tabela 4 resume um conjunto de abordagens de gerenciamento segundo o tipo de incerteza, além de sugerir um conjunto de sistemas de planejamento, coordenação e monitoramento mais adequado segundo o tipo de incerteza (etapa IV).

\subsection{Parte $C$ - Alinhamento das camadas}

Na proposição original de Phaal et al. (2004), o alinhamento entre as camadas do technology roadmap segue um processo lógico de causa-efeito. No presente trabalho, propõe-se um novo modo, que consiste em analisar a coevolução nas quatro dimensões da transição.

Os empreendedores poderão se basear na atividade 7 do PGT de cada uma das dimensões da transição. Após a definição dos milestones da transição em cada dimensão, os empreendedores deverão definir um milestones da coevolução entre as dimensões, com intuito de levar a inovação a superar o "vale da morte" e obter a decolagem das vendas. A coevolução entre as dimensões da transição define a ligação entre as camadas do TRM.

Parte do PGT é baseada em dados, principalmente, as atividades 1 e 2 . A outra parte é mais baseada em suposições ou cenários hipotéticos que os empreendedores tentam construir. Além disso, grande parte das decisões realizadas em cada uma das dimensões envolve lacunas de informações e incertezas. Para gerenciar a busca por informações e as incertezas, é proposto um processo de gerenciamento das incertezas, que corresponde à "parte B" da Figura 5. 


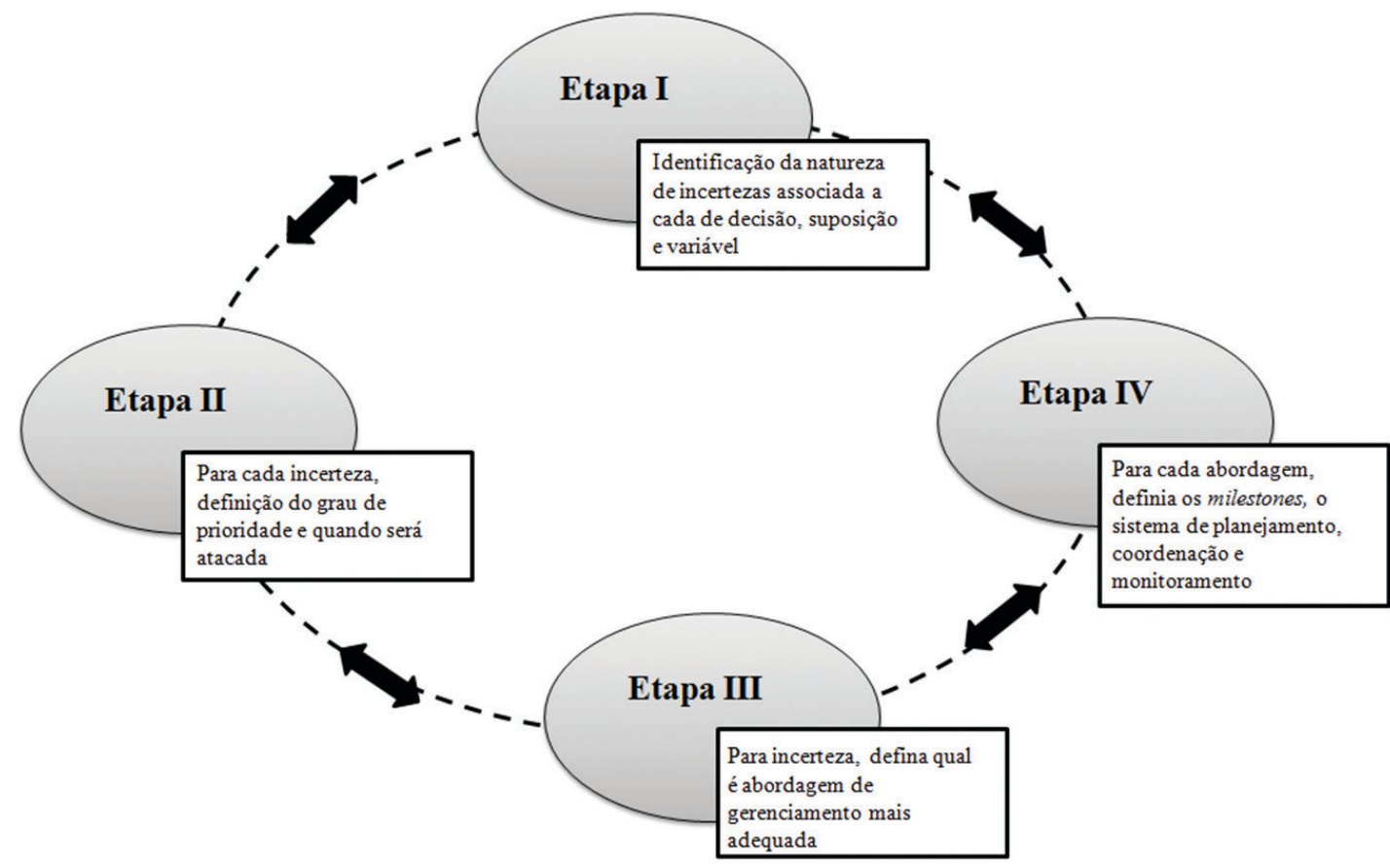

Figura 7. Gerenciamento das incertezas. Fonte: elaborado pelos autores.

Tabela 4. Abordagens de gerenciamento.

\begin{tabular}{|c|c|c|c|c|}
\hline Tipo de incerteza & $\begin{array}{l}\text { Abordagem de } \\
\text { gerenciamento }\end{array}$ & Sistema de planejamento & Coordenação e incentivos & $\begin{array}{c}\text { Sistema de } \\
\text { monitoramento }\end{array}$ \\
\hline Sem incerteza & $\begin{array}{l}\text { Planejar e atingir os } \\
\text { objetivos; rede de } \\
\text { atividades PERT e COM }\end{array}$ & $\begin{array}{l}\text { Sequenciamento das } \\
\text { atividades }\end{array}$ & $\begin{array}{l}\text { Definição dos } \\
\text { objetivos; definição das } \\
\text { responsabilidades }\end{array}$ & $\begin{array}{c}\text { Atendimento dos } \\
\text { objetivos; comparação } \\
\text { entre o planejado e o } \\
\text { atingido }\end{array}$ \\
\hline Variação & $\begin{array}{l}\text { Identificação do caminho } \\
\text { crítico; simulação de } \\
\text { cenários }\end{array}$ & $\begin{array}{l}\text { Sequenciamento das } \\
\text { atividades; simulação }\end{array}$ & $\begin{array}{l}\text { Definição dos } \\
\text { objetivos; definição das } \\
\text { responsabilidades }\end{array}$ & $\begin{array}{c}\text { Atendimento dos } \\
\text { objetivos; comparação } \\
\text { entre o planejado e o } \\
\text { atingido }\end{array}$ \\
\hline $\begin{array}{l}\text { Incerteza do tipo } \\
\text { foreseeable }\end{array}$ & Gerenciamento de risco & $\begin{array}{c}\text { Checklist dos riscos; } \\
\text { ações preventivas; planos } \\
\text { contingentes }\end{array}$ & $\begin{array}{l}\text { Planos contingentes e } \\
\text { contratos; ajustes mútuos } \\
\text { segundo os eventos }\end{array}$ & $\begin{array}{c}\text { Atendimento dos objetivos } \\
\text { contingentes (ramos da } \\
\text { árvore); } \\
\text { realização do } \\
\text { monitoramento do risco } \\
\end{array}$ \\
\hline $\begin{array}{l}\text { Incerteza do tipo } \\
\text { unforeseeable }\end{array}$ & Selecionismo & $\begin{array}{c}\text { Visão geral do } \\
\text { subproblema; definição } \\
\text { dos planos paralelos para } \\
\text { cada opção; definição } \\
\text { dos critérios para decisão } \\
\text { ex post; busca por sinais } \\
\text { fracos }\end{array}$ & $\begin{array}{l}\text { Critérios de parada; como } \\
\text { as incertezas estão sendo } \\
\text { reduzidas }\end{array}$ & $\begin{array}{c}\text { Incentivos para as } \\
\text { pessoas ligadas às opões } \\
\text { vencedoras e fracassadas }\end{array}$ \\
\hline $\begin{array}{l}\text { Incerteza do tipo } \\
\text { unforeseeable }\end{array}$ & $\begin{array}{c}\text { Aprendizado por tentativa } \\
\text { e erro }\end{array}$ & $\begin{array}{c}\text { Visão geral do } \\
\text { subproblema; } \\
\text { planejamento dos } \\
\text { experimentos; decisão } \\
\text { de quem pode mudar o } \\
\text { plano; busca por sinais } \\
\text { fracos }\end{array}$ & $\begin{array}{c}\text { Incentivo à } \\
\text { experimentação e busca } \\
\text { por novos conhecimentos }\end{array}$ & $\begin{array}{c}\text { Definição do ciclo } \\
\text { de experimentação; } \\
\text { especificação do que foi } \\
\text { aprendido; explicitar qual } \\
\text { o próximo problema a } \\
\text { ser resolvido; definir qual } \\
\text { problema vai ser resolvido }\end{array}$ \\
\hline Caos turbulência & Aprendizado & $\begin{array}{l}\text { Visão geral do } \\
\text { subproblema; tarefas para } \\
\text { o aprendizado; interação } \\
\text { rápida para reforçar o } \\
\text { aprendizado }\end{array}$ & $\begin{array}{l}\text { Relações baseadas na } \\
\text { confiança }\end{array}$ & $\begin{array}{c}\text { Definição do ciclo } \\
\text { de experimentação; } \\
\text { especificação do que foi } \\
\text { aprendido; explicitar qual } \\
\text { o próximo problema a } \\
\text { ser resolvido; definir qual } \\
\text { problema vai ser resolvido }\end{array}$ \\
\hline
\end{tabular}


Tabela 5. Síntese das contribuições.

\begin{tabular}{|c|c|c|c|c|}
\hline Spin-off & Contribuições & PGT & $\mathrm{Fl}$ & TRM \\
\hline $\mathrm{X} 1$ & Para a prática & $\begin{array}{l}\text { i) Permitiu aos empreendedores compreender a } \\
\text { conexão entre o ecossistema da inovação e do } \\
\text { negócio; } \\
\text { ii) Auxiliou a compor estratégias de transição na } \\
\text { forma que os fornecedores atuam, introduzindo } \\
\text { práticas de comércio justo, assim como permitiu } \\
\text { definir estratégias para acompanhar a evolução } \\
\text { do perfil dos clientes (do nicho até a solução } \\
\text { estabelecida); } \\
\text { iii) Auxiliou a firma a definir eventuais trajetórias } \\
\text { de desenvolvimento de recurso, competências e } \\
\text { capacitação, para acompanhar possíveis evoluções } \\
\text { da tecnologia e do mercado }\end{array}$ & $\begin{array}{l}\text { i) Permitiu aos empreendedores } \\
\text { enxergar os planejamentos e } \\
\text { desenvolvimentos da firma e da } \\
\text { inovação como um conjunto } \\
\text { de subproblemas inter- } \\
\text { relacionados com tipos e graus } \\
\text { diferentes de incertezas; } \\
\text { ii) Propiciou aos } \\
\text { empreendedores uma } \\
\text { abordagem mais contingencial } \\
\text { para o estabelecimento da firma } \\
\text { e para o desenvolvimento da } \\
\text { inovação }\end{array}$ & $\begin{array}{l}\text { Contribuiu para que } \\
\text { os empreendedores } \\
\text { alinhassem todas as } \\
\text { dimensões da transição }\end{array}$ \\
\hline $\mathrm{X} 1$ & $\begin{array}{l}\text { Para melhoria } \\
\text { e validação do } \\
\text { framework }\end{array}$ & $\begin{array}{l}\text { i) lluminou como poderia ocorrer a aplicação do } \\
\text { framework em situações reais; } \\
\text { ii) Ajudou a mostrar que o framework pode ser } \\
\text { iniciado em qualquer momento do processo PGT }\end{array}$ & $\begin{array}{l}\text { i) A aplicação contribuiu para } \\
\text { o melhor entendimento da } \\
\text { natureza contingencial do } \\
\text { framework; } \\
\text { ii) Contribuiu ao mostrar que } \\
\text { não é necessário terminar o } \\
\text { PGT para iniciar o Gl }\end{array}$ & $\begin{array}{l}\text { Contribuiu para } \\
\text { compreender como } \\
\text { ocorre o alinhamento } \\
\text { entre as camadas }\end{array}$ \\
\hline XI1 & Para a prática & $\begin{array}{l}\text { i) Permitiu compreender melhor as diferenças dos } \\
\text { direcionadores emergentes do nicho e do regime } \\
\text { sociotécnico; } \\
\text { ii) Permitiu definir estratégias ainda na fase } \\
\text { pré-competitiva, ou seja, antes do lançamento da } \\
\text { inovação no mercado }\end{array}$ & $\begin{array}{l}\text { i) Permitiu aos empreendedores } \\
\text { enxergar os planejamentos e } \\
\text { desenvolvimentos da firma e da } \\
\text { inovação como um conjunto } \\
\text { de subproblemas inter- } \\
\text { relacionados com tipos e graus } \\
\text { diferentes de incerteza }\end{array}$ & $\begin{array}{l}\text { Contribuiu para que } \\
\text { os empreendedores } \\
\text { alinhassem todas as } \\
\text { dimensões da transição }\end{array}$ \\
\hline X11 & $\begin{array}{l}\text { Para melhoria } \\
\text { e validação do } \\
\text { framework }\end{array}$ & $\begin{array}{l}\text { Mostrou que o framework pode ser aplicado } \\
\text { mesmo em fases pré-competitivas da inovação, } \\
\text { especialmente, quando as necessidades dos } \\
\text { clientes não estão claras e devem ser construídas }\end{array}$ & $\begin{array}{l}\text { Contribuição próxima da } \\
\text { aplicação obtida no spin-off X1 }\end{array}$ & $\begin{array}{c}\text { Contribuição próxima } \\
\text { da aplicação obtida no } \\
\text { spin-off } \mathrm{Xl}\end{array}$ \\
\hline
\end{tabular}

Fonte: elaborado pelos autores.

\subsection{Síntese das contribuições aportadas na aplicação do framework nas intervenções}

A Tabela 5 resume as principais contribuições aportadas pela aplicação do framework em duas situações reais. Essas contribuições não foram apenas para a melhoria do framework em si, mas também para o planejamento e o desenvolvimento da firma e da inovação nos respectivos spin-offs.

\section{Implicações do framework proposto para a teoria e para empreendedores acadêmicos}

Este trabalho procurou avançar em uma problemática que vem sendo estudada de forma fragmentada por diferentes pesquisadores de distintas áreas do conhecimento: como empreendedores acadêmicos podem articular o planejamento e o desenvolvimento da nova firma e da inovação. Esse esforço de pesquisa demandou que diversos temas fossem discutidos neste texto: planejamento estratégico de grandes e novas firmas, Technology Roadmapping e planejamento tecnológico, gerenciamento de projetos, gerenciamento de risco e incertezas, ecossistemas de inovação e de negócio, perspectiva sociotécnica da inovação como uma transição, inovação aberta, gestão de redes e capacitações dinâmicas. A fragmentação dessa discussão dificulta a compreensão, por parte dos empreendedores acadêmicos, de como se preparar melhor para superar desafios no intuito de explorar comercialmente o resultado de uma pesquisa acadêmica no mercado.

A principal contribuição desta pesquisa reside na proposição de um framework que procura integrar o planejamento e o desenvolvimento da nova firma ao planejamento e ao desenvolvimento da inovação. Esse framework oferece uma alternativa à abordagem proposta por Phaal et al. (2004) para o Technology Roadmapping, mais voltada para firmas estabelecidas. 0 framework considera o processo de inovação além da transformação técnica, incorporando uma visão mais ampla que inclui a dimensão sociológica e evolucionária (Geels, 2004) e operacionaliza os conceitos de incerteza imprevisível e a sua gestão (Pich et al., 2001), propondo um enfoque mais direcionado para o planejamento de novas firmas.

0 entendimento da inovação como transição oferece uma visão mais sistêmica do processo e dos efeitos da inovação, complementando as abordagens de inovação radical (ex.: 0'Connor, 2009), que focam mais apenas nos aspectos (ex.: determinadas características 
do produto), não contemplando a extensão e nem a trajetória. Assim, ao invés de diferenciar a inovação como radical ou incremental de forma unidimensional em termos de aspectos modificados, como empregam diversos autores (ex.: 0'Connor \& Ayers, 2005), a abordagem proposta neste trabalho permite entender os efeitos em diferentes dimensões e os diferentes atores implicados.

0 processo de gestão da transição (PGT), parte do framework proposto, permite que empreendedores articulem gerencialmente e estrategicamente um conjunto de decisões em uma perspectiva holística. Dessa forma, amplia-se o foco que originalmente se restringia apenas à firma, como sugerem Phaal et al. (2004), passando-se a contemplar todo um conjunto de estratégias de cooperação e competição no nicho, entre regime e nicho, constituindo o ecossistema da inovação e do negócio.

Um segundo processo que compõe o framework, o gerenciamento das incertezas (Gl), permite um entendimento de que o planejamento e o desenvolvimento da firma e da inovação constituem um sistema de subproblemas que pode exigir diferentes abordagens de gerenciamento, segundo a natureza das incertezas presentes em cada subproblema. 0 Gl vai além das abordagens de gerenciamento de risco (Block \& MacMillan, 1985) para lidar com as incertezas imprevisíveis, caos e turbulência. Ao contemplar esses diferentes tipos e graus de incerteza no framework, oferece-se uma abordagem mais ampla do que a proposta por Pich et al. (2001), permitindo aos empreendedores que desenvolvam estratégias e abordagens de gestão mais adequadas, segundo as contingências do negócio e da inovação. Além disso, o framework proposto adota uma abordagem cíclica e dinâmica, aproximando mais o planejamento da implantação e abandonando a abordagem do tipo one-fits-all, presente nos métodos tradicionais de planejamento. Isso implica, por exemplo, que o TRM não é congelado para a sua implantação como propõem Phaal et al. (2005). Mesmo com poucas informações iniciais, empreendedores podem rapidamente aplicar o framework para iniciar o desenvolvimento da firma e da inovação. À medida que o empreendimento se desenvolve e se avança no desenvolvimento da inovação, empreendedores podem incorporar as novas informações e conhecimentos ao planejamento, em uma perspectiva evolucionária e dinâmica.

Entretanto, há ainda vários desafios que devem ser superados para que esse framework seja validado. Inicialmente, é preciso testá-lo em diversos casos reais, no intuito de compreender melhor as vantagens, as desvantagens e as oportunidades para melhoria. As pesquisas conduzidas até o momento apontam que esse framework é mais indicado para spin-offs acadêmicos que nasçam para explorar uma inovação de natureza mais tecnológica. Será necessário investigar diferentes tipos de spin-offs para compreender as contingências e as limitações do framework. Pesquisas adicionais são necessárias para um melhor desenvolvimento e compreensão acerca de cada uma das dimensões e a relação entre elas. Uma interessante perspectiva a ser explorada seria compreender como o modelo de negócios se articularia ao framework proposto.

Há um conjunto emergente de abordagens de modelo de negócios, em especial o Lean Startup (Ries, 2012) e o modelo de negócio Canvas (Osterwalder \& Pigneur, 2010) que poderão ser integrados ao framework em pesquisas futuras A abordagem Lean Startup (Ries, 2012) possui elementos comuns com o framework desenvolvido neste trabalho, tais como ênfase no aprendizado, ciclo rápido de planejamento e entendimento de trajetória para produtos, indo desde o mínimo produto viável até a solução (projeto dominante) que irá se tornar referência para o mercado. Esses elementos poderão ser desenvolvidos em pesquisas futuras. Além disso, há outros elementos, tais como a ênfase no gerenciamento do cliente, que merecem ser tratados com maior profundidade em pesquisas posteriores.

De forma similar, abordagens visuais como a geração de modelo de negócio Canvas (Osterwalder \& Pigneur, 2010) podem ser articuladas ao Technology Roadmapping, integrando o planejamento estratégico e tecnológico à concepção e à implantação do modelo de negócio. Neste artigo foi apresentada uma visão inicial de modelo de negócio, que pode ser aprimorada com novas pesquisas, empregando conceitos e métodos das áreas do conhecimento supracitadas.

Finalmente, idealiza-se que este trabalho contribua como um referencial teórico para outros estudos que envolvam o planejamento e o desenvolvimento de spin-offs acadêmicos imbuídos na geração de inovação tecnológica.

\section{Referências}

Adner, R., \& Kapoor, R. (2010). Value creation in innovation ecosystems: how the structure of technological interdependence affects firm performance in new technology generations. Strategic Management Journal, 31, 306-333. http://dx.doi.org/10.1002/smj.821

Afuah, A. N., \& Bahran, N. (1995). The hypercube of innovation. Research Policy, 24(1), 51-76. http://dx.doi. org/10.1016/0048-7333(93)00749-J

Agarwal, R., \& Bayus, B. L. (2002). The market evolution and take-off of new products innovations. Management Science, 48(5), 1024-1041. http://dx.doi.org/10.1287/ mnsc.48.8.1024.167

Block, Z., \& MacMillan, l. C. (1985). Milestones for successful venture planning. Harvard Business Review, 63(5), 184-196. 
Brinckmann, J., Grichnik, D., \& Kapsa, D. (2010). Should entrepreneurs plan or just storm the castle? A metaanalysis on contextual factors impacting the business planning-performance relationship in small firms. Journal of Business Venturing, 25(1), 24-40. http:// dx.doi.org/10.1016/j.jbusvent.2008.10.007

Chapman, C. S. (1997). Project risk management. England: John Wiley \& Sons Ltda.

Cooper, R. G. (1994). Third-generation new product processes. Journal of Product Innovation Management, 11(1), 3-14. http://dx.doi.org/10.1016/0737-6782(94)90115-5

De Meyer, A., Loch, C. H., \& Pich, M. T. (2008). Managing project uncertainty: from variation to chaos. Sloan Management Review, 43(2), 59-68.

Delmar, F., \& Shane, S. (2003). Does business planning facilitate the development of new ventures? Strategic Management Journal, 24(12), 1165-1185. http://dx.doi. org/10.1002/smj.349

Dosi, G. (1982). Technological paradigms and technological trajectories. Research Policy, 11, 147-162. http://dx.doi. org/10.1016/0048-7333(82)90016-6

Eisenhardt, K. (1989). Building theories from case study. Research Academy of Management, 14(4), 532-550.

Geels, F. W. (2002). Technological transitions as evolutionary reconfiguration processes: a multi-level perspective and a case-study. Research Policy, 31, 1257-1274. http:// dx.doi.org/10.1016/j.respol.2004.01.015

Geels, F. W. (2004). From sectoral systems of innovation to socio-technical systems insishts about dynamics and change from sociology and institutional theory. Research Policy, 33, 897-920. http://dx.doi.org/10.1016/S00487333(02)00062-8

Gomes, L. A. V., \& Salerno, M. S. (2010). Modelo que integra processo de desenvolvimento de produto e planejamento inicial de spin-offs acadêmicos. Gestão \& Produção, 17, 245-255. http://dx.doi.org/10.1590/ S0104-530X2010000200003

Heirman A., \& Clarysse, B. (2007). Which tangible and intangible assets matter for innovation speed in start-ups. Journal of Product Innovation Management, 24), 303315.http://dx.doi.org/10.1111/j.1540-5885.2007.00253.x

Hughes, T. P. (1987). The evolution of large technological systems. In W. E. Bijker, T. P. Hughes \& T. Pinch (Eds.), The social construction of technological systems: new directions in the sociology and history of technology. Cambridge: MIT Press.

Lee, S., Yoon, B., Lee, C., \& Park, J. (2009). Business planning based on technological capabilities: patent analysis for technology-driven roadmapping. Technological Forecasting Social Change, 72(5), 769-786. http://dx.doi. org/10.1016/j.techfore.2009.01.003

Lee, S., \& Park, J. (2005). Customization of technology roadmaps according to roadmapping purposes: Overall process and detailed modules. Technological Forecasting and Social Change, 72(5), 567-583. http://dx.doi. org/10.1016/j.techfore.2004.11.006

Leifer, R., O'connor, G. C., \& Rice, M. P. (2001). Implementing radical innovation in mature firms: the role of hubs. Academy of Management Executive, 15(3), 102-113. http://dx.doi.org/10.5465/AME.2001.5229646

Leydesdorff, L., \& Etzkowitz, H. (1998). The triple helix as a model for innovation studies. Science and Public Policy, 25(3), 195-203.
Liberman, M., \& Montgomery, B. (1988). First-mover (dis) advantages: retrospective and link with the resourcebased view. Strategic Management Journal, 19, 11-25.

Loch, C. H., Solt, M. E., \& Bailey, E. M. (2008). Diagnosing unforeseeable uncertainty in a new venture. Journal of Product Innovation Management, 25(1), 28-46. http:// dx.doi.org/10.1111/j.1540-5885.2007.00281.x

Lundvall, B. A. (1988). Innovation as an interactive process: from user-producer interaction to the national system of innovation. In G. Dosi, C. Freeman, R. Nelson, G. Silverberg, \& L. Soete (Eds.), Technical change and economic theory. London: Pinter.

Martinich, J. S. (1997). Production and operations management: an applied modern approach. New York: John Wiley \& Sons. PMid:9411528.

McGrath, R. G., \& MacMillan, l. C. (1995). Discovery-driven planning. Harvard Business Review, 73(4), 44-54.

Mintzberg, H. (1994). The rise and fall of strategic planning. New York: The Free Press. PMid:8089715.

Nelson, R. R., \& Sampat, B. N. (2001). Making sense of institutions as a factor shaping economic performance. Journal of Economic Behavior \& Organization, 44, 31 54. http://dx.doi.org/10.1016/S0167-2681(00)00152-9

O'Connor, G. C. (2009). Sustaining breakthrough innovation. Research Technology Management, 52(3), 12-14.

0'Connor, G. C., \& Ayers, A. D. (2005). Building a radical innovation competency. Research Technology Management, 48(1), 23-32.

Osterwalder, A., \& Pigneur, Y. (2010). Business model generation: a handbook for visionaries, game changers, and challengers. New York: Wiley.

Phaal, R., Farrukh, C., \& Probert, D. (2004). Technology roadmapping - planning framework for evolution and revolution. Technological Forecasting \& Social Change, 71, 5-26. http://dx.doi.org/10.1016/S00401625(03)00072-6

Phaal, R., Farrukh, C., \& Probert, D. (2005). Developing a technology roadmapping system. In T. R. Anderson, D. F. Kocaoglu \& T. U. Daim (Eds.), Technology management: a unifying discipline for melting the boundaries. Portland: $\quad$ PICMET. http://dx.doi.org/10.1109/ PICMET.2005.1509680

Pich, M. T., Loch, C. H., \& Meyer, A. (2001). On uncertainty, ambiguity, and complexity in project management. Management Science, 4, 356-371.

Porter, M. E. (1980). Competitive strategy: techniques for analyzing industries and competitors. New York: Free Press.

Rabechini Junior, R., \& Carvalho, M. M. (2012) Relacionamento entre gerenciamento de risco e sucesso de projetos. Produção, 23(3), 570-581. http://dx.doi. org/10.1590/S0103-65132012005000091

Rice, M. P., O'Connor, G. C., \& Pierantozzi, R. (2008). Implementing a learning plan to counter project uncertainty. MIT Sloan Management Review, 49(2), 53-62.

Ries, E. (2012). A Startup Enxuta. São Paulo: Lua de Papel.

Roberts, E. B. (1991). Entrepreneurs in high technology: lessons from MIT and beyond. New York: Oxford University Press. http://dx.doi.org/10.1093/acprof:o so/9780195067040.001.0001 
Sarasvathy, S. D. (2001). Causation and effectuation: towards a theoretical shift from economic inevitability to entrepreneurial contingency. Academy of Management Review, 26(2), 243-263.

Shane, S. (2004). Academic entrepreneurship: university spinoffs and wealth creation. Aldershot: Edward Elgar. http://dx.doi.org/10.4337/9781843769828

Sommer, S. C., Loch, C. H., \& Dong, J. (2009). Managing complexity and unforeseeable uncertainty in startup companies: an empirical study. Organization Science, 20, 118-133. http://dx.doi.org/10.1287/ orsc. 1080.0369

Sommer, S. C., \& Loch, C. H. (2004). Selectionism and learning in projects with complexity and unforeseeable uncertainty. Management Science, 50(10), 1334-1347. http://dx.doi.org/10.1287/mnsc. 1040.0274
Thiollent, M. (1997). Pesquisa-ação nas organizações. São Paulo: Atlas.

Tidd, J., Bessant, J., \& Pavitt, K. (2005). Managing innovation: integrating technological, market and organizational change. 3rd. ed. New York: John Wiley \& Sons.

Utterback, J. M. (1994). Mastering the dynamics of innovation. Boston: Harvard Business School Press.

Verbong, G. P. J., \& Geels, F. W. (2010). Exploring sustainability transitions in the electricity sector with socio-technical pathways. Technological Forecasting \& Social Change, 77(8), 1214-1221. http://dx.doi. org/10.1016/j.techfore.2010.04.008

Vohora, A., Wright, M., \& Lockett, A. (2004). Critical junctures in the development of university high-tech spinout companies. Research Policy, 33(1), 147-175. http://dx.doi.org/10.1016/S0048-7333(03)00107-0

\title{
Innovation as a transition process: proposition of a framework for the process of creating and developming academic spin-offs
}

\begin{abstract}
An academic spin-off is a new type of firm that often comes to exploit a radical innovation capable of creating a new market or defying the rules of an established industry. Employing a combination of literature research, multiple case studies and interventions based on action research, this study aims to contribute in two ways to the literature on innovation and entrepreneurship. First, it proposes a concept of innovation as a transition in three dimensions: level (deviation from a rule), length (number of features and actors involved) and trajectory (sequence of innovations over time). The second contribution is building a framework that has a non-linear and recursive structure and integrates innovation with planning and the development of spin-offs, thereby addressing uncertainty management. Finally, it is concluded that the proposed framework can help entrepreneurs, investors and universities with the challenge of creating a firm to exploit a radical innovation.
\end{abstract}

\section{Keywords}

Innovation. Planning. Technology roadmap. Academic spin-offs. Uncertainty. 